\title{
Populismo en las declaraciones de independencia americanas El caso de Venezuela
}

\author{
Populism in the declarations of American independence \\ The case of Venezuela
}

Jacobo Calvo Rodríguez*

\begin{abstract}
Resumen: Se explora la capacidad de La Razón Populista ${ }^{1}$ para interpretar fenómenos políticos que no tienen únicamente que ver con los movimientos populistas clásicos, sino con movimientos incuestionablemente políticos e históricos. Más concretamente, este trabajo se pregunta si la teoría del populismo de Laclau tiene capacidad para interpretar un fenómeno histórico como el texto contenido en una declaración de independencia. Así, la pregunta que guiará el texto será: ¿es el populismo de Laclau, como el propio autor indica, un marco teórico con el que se pueden interpretar diversos fenómenos políticos y no solo aquellos vinculados a las imágenes del populismo clásico o tradicional?
\end{abstract}

Palabras clave: Discurso, Populismo, Independencia, Declaración

\begin{abstract}
In this article, it is explored the possibility of using La Razón Populista to interpret political phenomena that have nothing to do with classic populist movements, but rather with unquestionably political and historical movements. More specifically, we raise the question of whether Laclau's theory of populism is valid to interpret a historical phenomenon such as the text of a declaration of independence. Thus, the question guiding this essay is: is Laclau's populism, as the author himself indicates, a theoretical framework that can be used to interpret various political phenomena, and not only those related to the images of classical or traditional populism?
\end{abstract}

Keywords: Discourse, Populism, Independence, Declaration

Recibido: 21 febrero 2019 Aceptado: 16 abril 2019

\section{Marco teórico: el populismo de Ernesto Laclau}

El populismo para Ernesto Laclau es una construcción discursiva de la realidad política que establece una frontera entre la mayoría (el pueblo) y la minoría (la oligarquía). El "pueblo" sería el sujeto mayoritario excluido por el gobierno minoritario de los "oligarcas", origen de los problemas de la comunidad política.

Así, para Laclau, el populismo es la frontera discursiva que se marca entre un "ellos" ostentadores del poder y que encarnan el "mal gobierno"- y un "nosotros" -verdaderos merecedores del poder político por ser los oprimidos de ese "mal gobierno". El populismo se presenta como el discurso propio de la plebs con voluntad de transformarse en populus. La plebs es plebs por considerarse

\footnotetext{
* Dr (C) Universidad de La República, Instituto de Ciencia Política, Uruguay, jacobo.calvo@live.com

${ }^{1}$ Ernesto Laclau: La Razón Populista, FCE (2005).
} 
excluida del populus, que es el pueblo "legítimo" que participa activamente en la comunidad política. Todo régimen político tiende a neutralizar la existencia construida de esa plebs mediante un discurso institucionalista que representa a un populus ${ }^{2}$ en ocasiones mayor y en ocasiones menor. Este discurso institucionalista-opuesto al populista-, tiende a neutralizar el conflicto que se da en las comunidades políticas, presentándose como el representante de la totalidad de la comunidad y resolviendo los conflictos mediante una lógica diferenciada para cada uno de ellos. "[La] noción de que un grupo tal que, mediante la organización, hubiera asumido todas las funciones del individuo y hubiera eliminado la noción de un líder se corresponde, casi punto por punto, con una sociedad totalmente gobernada por lo que hemos denominado lógica de la diferencia"3.

Esta comunidad dejaría de ser política, y pasaría a ser una sociedad en la que los problemas se solucionan de manera técnica. De esta manera, según Laclau, cuánto más populista es un movimiento, más político es. Como en realidad nunca llega a existir esta totalidad, siempre es necesaria una frontera que Laclau denomina como populista ${ }^{4}$. De ahí que no tengamos que preguntarnos si un movimiento es o no populista, sino cuán populista es ${ }^{5}$. Precisamente, gracias a la existencia de esa frontera implícita, es por lo que un discurso institucionalista puede ser considerado como político. A pesar de que la frontera discursiva pueda no ser explícita, puede darse de manera velada o normalizada, dándose por hecho a quiénes excluye debido a una operación hegemónica ${ }^{6}$.

En contraposición a esa lógica de la diferencia de tratar cada conflicto por separado, está la lógica de la equivalencia. Lógica propia del populismo, que aglutina bajo un mismo significante vacío -por ejemplo "pueblo"- una serie de demandas anteriormente aisladas y luego unificadas bajo un mismo discurso y una voluntad impugnadora del orden oligárquico o propio de las minorías.

\section{Justificación}

El populismo de Ernesto Laclau ha terminado por ser un término polisémico con toda una serie de cuestionamientos según dónde se centre la atención. Aboy Carlés ha centrado su crítica en el elemento institucionalista enfrentado al populista, concluyendo que no son elementos contradictorios sino tensionados y propios de todo ordenamiento político 7 . Sebastián Barros ha planteado el populismo como un momento de ruptura ${ }^{8}$. Otro de los aspectos discutidos alrededor del concepto teórico de Laclau, y posiblemente el más polémico, es la sinonimia que hace el autor argentino entre hegemonía, política y populismo. Cuestión inteligentemente expuesta por Benjamín Arditi en el ya citado artículo. Vale la pena aclarar este último punto.

No se pretende en este trabajo demostrar que el populismo es "lo político" o la única manera de construir discursos políticos como llega a explicitar el propio Laclau? ${ }^{9}$ Las fronteras entre actores no solo se construyen en términos pasionales o de mayorías contra minorías. También pueden construirse a través de discursos puramente ideológicos, como el conflicto habitualmente planteado entre derecha e izquierda. O también en términos economicistas que enfrentan lo racional a lo irracional ${ }^{10}$.

Lo que se pretende es afirmar que lo que Laclau denomina populismo es una dinámica histórica "habitual" lejos de las lecturas que lo reducen a una fase histórica de modernización

\footnotetext{
2 Laclau, op. cit. p. 108-113.

3 Ibid. p. 111

${ }^{4}$ Benjamín Arditi: “¿Populismo es hegemonía es política? La teoría del populismo de Ernesto Laclau”. Constellations, Vol. 17, No. 2 (2010), 488-497.

${ }^{5}$ Ernesto Laclau: “Populismo: ¿qué nos dice un nombre?”. En Francisco Panizza (ed.), Elpopulismo como espejo de la democracia. Buenos Aires, Fondo de Cultura Económica (2009), pp. 51-70

${ }^{6}$ Laclau op. cit. (2005); Antonio Gramsci: La política y el Estado moderno, Diario Público (2009).

${ }^{7}$ Gerardo Aboy Carlés: "Las dos caras de Jano: acerca de la compleja relación entre populismo e instituciones políticas" en Pensamento Plural, n 7 junho-dezembro (2010); “Tensiones entre populismo y democracia liberal” en Área Teoría Politica, Panel III: Populismo e identidades políticas en América Latina, $8^{\circ}$ Congreso Latinoamericano de Ciencia Política, Lima (2015).

${ }^{8}$ Sebastián Barros: "Espectralidad e Inestabilidad Institucional. Acerca de la Ruptura Populista" en Estudios Sociales, 30(1) (2006), pp. 145-162.

${ }^{9}$ Laclau, op. cit. (2005), p. 195.

${ }^{10}$ John Markoff y Verónica Montecinos: "El irresistible ascenso de los economistas" en Desarrollo Económico, Vol. 34, No. 133, p. 3-29 Apr. - Jun. (1994).
} 
industrial en Latinoamérica ${ }^{11}$; o a un régimen autoritario que sigue un determinado tipo de lógica política enfrentada con las instituciones ${ }^{12}$. En definitiva, se pretende rescatar la dimensión histórica que otorga Laclau al populismo y contrastarla con un estudio de caso que tome las precauciones metodológicas necesarias. Los estudios empíricos terminan desfigurados en La Razón Populista, ya que los ejemplos históricamente lejanos que utiliza Laclau no están profundamente desarrollados. Este contraste de lo teórico con lo empírico en momentos históricamente lejanos ha gozado de muy poca atención por parte de los investigadores en el caso referido.

En este sentido, la posibilidad de encontrar elementos populistas dentro de procesos que no han sido interpretados desde esta óptica supondría, por un lado, aportar mayor riqueza teórica a un proceso estudiado fundamentalmente desde la historiografía. Por otro lado, reforzar la teoría de Laclau mediante un estudio de caso empírico desarrollado con mayor rigurosidad que la que ofrece su obra.

Habría que aclarar dos cuestiones para comprender por qué es posible utilizar la teoría del populismo de Laclau para interpretar declaraciones de independencia y no solo fenómenos universalmente reconocidos como populistas sea cual sea la definición utilizada de "populismo". En primer lugar, se aclarará por qué es posible desde el punto de vista cronológico. Y en segundo lugar, se debe aclarar cuál es la ideología que subyace detrás de la declaración de independencia venezolana, ya que Laclau establece que el populismo carece de ideología como tal y puede ser un discurso construido por cualquier actor político al margen de sus ideas y sus políticas públicas.

El propio autor argentino toma ejemplos históricos tradicionalmente no populistas $-\mathrm{O}$ considerados populistas - para justificar su teoría, como en el caso de Ataturk ${ }^{13}$. Además, en un intento obvio por plantear el populismo como parte de las dinámicas histórico-políticas -y no solo como estrictamente contemporáneo o del siglo XX- pone el ejemplo de la Revolución Francesa y del cartismo inglés. De la Revolución Francesa se vale para explicar las lógicas de la equivalencia que teóricamente ocurren en el populismo:

En el curso de la Revolución Francesa, y especialmente durante el período jacobino, el pueblo, como sabemos, constituyó una construcción equivalencial, y la totalidad de la dinámica política del período sería ininteligible si no la entendiéramos en términos de la tensión existente entre la universalidad de la cadena equivalencial y la particularidad de las demandas de cada uno de los eslabones. (...) Todo el período está marcado por la tensión entre las demandas de los trabajadores y el discurso equivalencial de la democracia popular radical. ${ }^{14}$

Por otro lado, Laclau se sirve del cartismo para explicar, en el contexto de la Revolución Industrial, un discurso con una frontera amigo-enemigo que adoptan los militantes cartistas para nombrar la realidad política de su tiempo:

(...) éste era el discurso que dividía a la sociedad en dos campos (...). Lo que es característico de ese discurso es que no constituía un discurso de la clase trabajadora, sino un discurso popular dirigido en principio, a todos los productores contra los "ociosos". La distinción no era principalmente entre las clases dirigentes y las clases explotadas en un sentido económico, sino más bien

11 Cristóbal Rovira y Raimundo Frei: "El populismo como experimento político: historia y teoría política de una ambivalencia" en Revista de Sociología, no 22, Facultad de Ciencias Sociales - Universidad de Chile (2008). pp. 117-140.; Carlos Vilas: "¿Populismos reciclados o neoliberalismo a secas? El mito del "neopopulismo" latinoamericano" en Rev. Venez. de Econ. y Ciencias Sociales, 2003, vol. 9, no 3 (mayo-agosto), pp.13-36.

12 Frei y Rovira, op. cit.; Flavia Freidenberg: ¿Qué es el populismo? Enfoques de estudio y una nueva propuesta de definición como un estilo de liderazgo, Instituto de Iberoamérica USAL (2013). En línea:

http://www.academia.edu/2367975/_Qu\%C3\%A9_es_el_populismo_Enfoques_de_estudio_y_una_nueva_propuesta_d e definici $\%$ C3\%B3n como un estilo de liderazgo (consultado 20/08/2015)

${ }^{13}$ Laclau, op. cit. (2005) p. 258-265

14 Ibíd. p. 105 
entre los beneficiarios y las víctimas de la corrupción y el monopolio del poder político. ${ }^{15}$

Por otro lado, cabe admitir que ya se ha especulado con la capacidad de la teoría populista para ser aplicada a otros discursos políticos. J. Hillis Miller escribe lo siguiente: "Los nombres que da Laclau a la clase de cambio que espera son "hegemonía" (tomado de Gramsci) y "emancipación(es)", que es además el título de uno de sus libros (Emancipación y diferencia). Las revoluciones y las "declaraciones de independencia" exitosas son una de las formas de ese cambio (...)."16

En segundo lugar, se cumple con lo explicitado por Laclau en su concepción del populismo como a-ideológico, pudiendo existir populismo liberal, republicanista, socialista, etc. Tomaremos el caso venezolano dado que está inspirado en un pensamiento liberal ${ }^{17}$. Todo ello, aunque la independencia fue el ideal alrededor del cual se concentraron toda una serie de demandas populares. Sin embargo, esta declaración está inspirada en el documento de 1776 en los Estados Unidos ${ }^{18}$, influenciada por una ideología republicanista ${ }^{19}$.

\section{Teoría del discurso y metodología o cómo huir del anacronismo}

\section{La Teoría del discurso}

\section{a. ¿Qué es el discurso?}

El discurso es un conjunto de acciones sociales que se diferencian unas de otras porque se relacionan entre sí. Ninguna palabra tiene un significado en sí misma, sino que toma significado cuando se diferencia de las demás. Dichas acciones y palabras se constituyen, por tanto, durante la misma relación entre ellas y no tienen sentido en sí mismas. Una relación que, por lo demás, es construida a través del lenguaje y que en conjunto forma un complejo relacional que es el discurso ${ }^{20}$.

En ocasiones, se ha definido el discurso como aquello que nombra, con mayor o menor fortuna, la realidad. La cual, mediante procedimientos también más o menos acertados, podemos asir y comprender. De esta manera, habría verdades que podríamos ir descubriendo a lo largo de la historia. Esta consideración sugiere que el ser humano se mueve por intereses instrumentales que, si se comparten, se convierten en colectivos. Por tanto, es una cuestión de unir intereses objetivos comprobables $^{21}$.

Se hace así depender el discurso de esos intereses. El discurso sería, simplemente, una elaboración interesada con el fin de comunicar unos objetivos o demandas. Sin embargo, la teoría del discurso de la que se vale este estudio no contempla la existencia, como tal, de estos intereses objetivos, sino que plantea que los intereses son construidos por determinados actores en un momento histórico determinado.

\footnotetext{
${ }^{15}$ Gareth Stedman Jones: G. Stedman Jones, "Rethinking Chartism", en Languages of class. Working Class History 1832-1902, Cambridge (Inglaterra), Cambndge Press, 1983 cit. en Laclau op. cit. (2005) p. 118.

16 J. Hillis Miller: "Hacerse cargo de una tarea. Momentos de decisión en el pensamiento de Ernesto Laclau" en Critchley, Simon y Marchart, Oliver (comp.): Laclau, aproximaciones críticas a su obra, FCE (2008), pp. 269-279.

17 M. Belin, y V. Vázquez: "Independencia y estado-nación en Venezuela desde los regímenes de la gubernamentabilidad" en Documentos de trabajo IELAT, n' 17 (2010), 24-48.

18 Armitage, David: The Declaration of Independence: A Global History. Cambridge, MA: Harvard University Press (2007).

Armitage, David: Declaraciones de independencia, 1776-2011: del derecho natural al derecho internacional. En línea: http://scholar.harvard.edu/armitage/files/declaraciones.pdf (consultado 06/09/2015)

${ }^{19}$ Hannah Arendt: Sobre la Revolución, Madrid, Alianza (1992);

${ }^{20}$ Laclau, op. cit. (2005)

${ }^{21}$ J. M Colomer: "La teoría 'económica' de la política" en Fernando Vallespín (ed.): Historia de la Teoría Política, Vol. 6 La reestructuración contemporánea del pensamiento político. Madrid, Alianza (1995).
} 


\section{b. Premisas: la teoría del discurso como punto de partida}

Según este punto de partida, los discursos "dan la posibilidad de percepción, pensamiento y acción [y] depende[n] de la estructuración de un determinado campo de significación" 22 , siendo los campos de significación relatos dentro de los cuales cobran significado las prácticas y los conocimientos. De esta manera, los discursos son cambiantes, contingentes y, por tanto, históricos al ser un conjunto articulado de significados y significantes relativamente estructurados. En palabras de Howarth: "todos los objetos y prácticas tienen un significado" y "los significados sociales son contextuales, relacionales y contingentes". De esa manera, los discursos dependen "de exteriores discursivos que parcialmente constituyen dichos órdenes, mientras que potencialmente los subvierten"'23.

Es relacional porque, como decíamos, diferentes significados y significantes se relacionan entre sí, dado que toda acción puede ser interpretable desde estructuras discursivas. Así, toda práctica política está cargada de un significado construido discursivamente, por lo que no existiría una diferencia entre praxis y discurso. En definitiva, la teoría del discurso se inscribiría dentro de la hermenéutica en las ciencias sociales. Es decir, busca hacer interpretaciones sobre las interpretaciones que hacen los actores sociales. De esa manera las prácticas e instituciones estarían fundamentadas en creencias subjetivas de los propios actores sociales ${ }^{24}$.

En este sentido, conviene aclarar que, desde la teoría del discurso, no se considera que lo que podríamos llamar "real-concreto" es la materia prima a partir de la cual se parte para cualquier análisis ${ }^{25}$. De hecho, los teóricos del discurso no conciben la distancia existente entre lo real-concreto y el propio investigador, ya que entienden que hay que considerar al propio sujeto como un "siempre ya" -en términos heideggerianos- dentro de un mundo de continuas prácticas cargadas de sentido. Prácticas con sentido que a su vez son las que nos permiten identificar los objetos.

Al igual que para Michel Foucault ${ }^{26}$, en la aplicación de la teoría del discurso no importa como tal la veracidad o falsedad de los enunciados, sino la manera en que determinados discursos adquieren el carácter de veraz ${ }^{27}$. Las interpretaciones hechas a través de esta teoría tampoco pretenden erigirse como verdaderas o falsas y no pretenden establecer dicha división, sino que son "candidatas a la verdad o a la mentira" 28 , lo que no quita que todo estudio esté sujeto a las exigencias del rigor necesario para la actividad científica.

Las diferencias entre los estudios discursivos de Foucault y la propuesta de los teóricos del discurso se encontrarían fundamentalmente en dos puntos. El primero de ellos sería que el autor francés reconoce un ámbito que es propio del discurso y otro que no lo es, es decir, establece una diferenciación entre lo discursivo y lo no-discursivo. Lo discursivo estaría entonces condicionado por la tecnología, las instituciones o la economía, por lo que habría algo externo al discurso que lo condiciona. La segunda diferencia es que Foucault plantea el discurso como un campo donde se "unifican las producciones intelectuales" 29 de una determinada época. Esas producciones intelectuales serían lo que llama "sociedades del discurso", una policía ${ }^{30}$ del discurso que establece lo que es nombrable - y en qué términos-y lo que no lo es. Pese a que en esto último de lo que es nombrable/decible/pensable los teóricos del discurso coinciden, no coinciden en el hecho de que sean estrictamente producciones intelectuales venidas desde determinados grupos localizables, sino

22 Ernesto Laclau: "Discourse" en Gooding and Petit (eds.): The Blacwell Companion to Contemporary Political Philosophy, Oxford, Blackwell (1993), pp. 431-437. Cit. en Íñigo Errejón: La lucha por la hegemonía durante el primer gobierno del MAS en Bolivia (20062009): un análisis discursivo [Tesis Doctoral], UCM (2012). p. 167

${ }^{23}$ David Howarth: "Aplicando la Teoría del Discurso: el Método de la Articulación” en Studia Politicae, No. 5 (2005) pp. $37-$ 88. p. 39

${ }^{24}$ Howarth, op. cit. (2005)

25 Ibid.

${ }^{26}$ Michel Foucault: El orden del discurso, Barcelona Tusquets (1992).

${ }^{27}$ Errejón, op. cit.

${ }^{28}$ Howarth op. cit. (2005), p. 58

${ }^{29}$ Errejón op.cit. p. 169

${ }^{30}$ Foucault op. cit. p. 31 
que, por el contrario, y como decíamos antes, la teoría del discurso entiende que no hay nada exterior a lo comprendido desde lo discursivo, por lo que los diferentes discursos son relacionales ${ }^{31}$.

Esta cuestión sobre lo relacional del discurso lo toma prestado Ernesto Laclau del lingüista Ferdinand Sausurre. Según Sausurre el lenguaje está estructurado de manera que los significantes, en sí mismos, no tienen un significado, sino que cada palabra es definida en relación al resto. En otras palabras, "algo" es "algo" porque no es el resto de las cosas y no porque "algo" tenga un significado en sí mismo. Para Sausurre, el lenguaje es forma y no sustancia ${ }^{32}$. Las diferencias entre Sausurre y Laclau son fundamentalmente dos. La primera sería que, según el primero, a cada significante corresponde un solo significado. La segunda es que, según el mismo autor, el sentido de las oraciones depende exclusivamente de la voluntad del hablante. Sin embargo, para Laclau “(...) de lo que se trata entonces es de comprender estas reglas que organizan el discurso. El uso de la lingüística para el estudio de las relaciones sociales discursivas significa 'politizar' la lingüística (...). Entramos así en el terreno inestable del conflicto político." 33 De este modo, el discurso no sería el epifenómeno de una realidad objetiva, sino que, como forma contingente y no como sustancia, sería lo que dota de sentido a la propia realidad.

\section{c. Los actores en la teoría del discurso}

Como se venía diciendo, la teoría del discurso contempla el estudio de subjetividades e interpretaciones, no de hechos calificables como objetivos, por lo que a la hora de estudiar a los actores políticos no concibe su discurso como una expresión de intereses de sujetos preexistentes ${ }^{34}$.

De esta manera, definir el sentido siempre encuentra adversarios que también querrían definirlo en sus términos, lo que produce un enfrentamiento que "repliega" a cada uno de los actores hacia sí mismo. Es decir, es la oposición misma la que crea las identidades. A cada una de las identidades las vincula un determinado discurso y unos determinados enunciados con los que se sienten identificados, a través de los cuales se diferencian del resto ${ }^{35}$. En definitiva, es el propio conflicto el que constituye el significado de las identidades.

Llegado este punto, no debemos pensar que se hace referencia a la existencia de discursos verdaderamente liberadores y otros verdaderamente dominadores. Todo discurso supone "crear un mundo nuevo de leyes, privilegios, subordinaciones y delimitaciones" 36 , como decía Nietzsche. Todo discurso contempla límites que no se pueden traspasar. En palabras de Foucault:

(...) que existan sistemas de enrarecimiento no quiere decir que, por debajo de ellos, más allá de ellos, reinaría un gran discurso ilimitado, continuo y silencioso, que se hallaría, debido a ellos, reprimido o rechazado, y que tendríamos por tarea que levantar restituyéndole finalmente el habla ${ }^{37}$.

En otras palabras, no existe un discurso previo a su elaboración; ni tampoco una serie de realidades esenciales dispuestas a ser descubiertas y ordenadas en una lógica liberadora. Por tanto, tampoco existen discursos dominadores que reprimen ese discurso verdaderamente liberador. No sería por tanto una cuestión de profundidad -en el sentido de profundizar hasta el discurso esencialsino una cuestión de "externalidad" o "internalidad" a una totalidad que, pese a ser "total", tiene límites ${ }^{38}$. Es decir: qué discursos se encuentran dentro del sentido común y cuáles son aquellos que se quedan fuera del mismo:

\footnotetext{
${ }^{31}$ Errejón, op. cit.

32 Ibid. p. 168

${ }^{33}$ Ibid. p. 170

${ }^{34}$ Ibid.

${ }_{35}$ David Howarth: "La teoría del discurso" en Marsh, David y Stoker, Gerry (eds.): Teoría y métodos de la ciencia política, Alianza (1995), pp. 125-142; Errejón, op. cit.

${ }^{36}$ Friedrich Nietzsche: Sobre verdad y mentira en sentido extramoral (1873) en línea:

https://www.lacavernadeplaton.com/articulosbis/verdadymentira.pdf

${ }^{37}$ Foucault op. cit. p. 43-44

${ }^{38}$ Ernesto Laclau: Philosophical roots of discourse theory. En línea:
} 
(...) ninguna identidad está cerrada en sí misma, sino que es sometida a desplazamientos constantes en términos de cadenas de combinación y substitución. Es constituida a través de procesos esencialmente tropológicos que no se refieren a ningún fundamento último trascendental. ${ }^{39}$

De esta manera descartamos la idea de una superestructura dependiente de un sistema "esencial" o "más profundo" que sería, por ejemplo, la realidad económica. Todo lo contrario, sería el propio discurso el que ordena y reordena la realidad bajo la dirección de determinados actores políticos que son capaces de introducir su discurso en la comunidad política de manera efectiva. De ahí que "para la teoría del discurso la vida social puede ser descrita en términos de una retórica generalizada." 40

Por último, dos puntualizaciones. La primera, es que la teoría del discurso en ningún caso niega o pone en cuestión la existencia del mundo externo a lo simbólico o a lo discursivo o al pensamiento. Lo que se afirma es que la existencia misma de los objetos no es lo que tiene incidencia en la realidad política, sino la interpretación que se hace de los mismos a través de estructuras simbólicas o discursivas. Es por eso que a los investigadores que siguen esta línea de investigación no les interesa tanto estudiar los objetos políticos en relación a "lo que son en realidad", sino a las formas que toman dentro del conflicto político ${ }^{41}$.

La segunda, es que la teoría del discurso plantea que, efectivamente, existen discursos sedimentados en el espacio de una coyuntura dada. Esos discursos sedimentados son los que constituyen las "condiciones de posibilidad" 42 de toda actividad política. En otras palabras, la teoría del discurso no puede ser concebida como un planteamiento voluntarista que formula la posibilidad de construcciones políticas ex novo. Sin embargo, estas precondiciones de partida no se entienden como hechos objetivos, sino que son producto de otra serie de símbolos y discursos previamente construidos. Esto es lo que Howarth denomina como "lógicas sociales" en contraposición con las "lógicas políticas". Mientras que las lógicas políticas serían aquellas que constituyen las prácticas políticas de un determinado momento histórico, las lógicas sociales son las mismas prácticas sociales cotidianas que devienen de las lógicas políticas ${ }^{43}$.

De esta manera, la teoría del discurso huiría tanto de concepciones plenamente voluntaristas que interpretan las acciones y los discursos en el vacío; como de otra serie de concepciones plenamente estructuralistas en las que lo político termina carente de toda autonomía.

\section{d. Significante vacío y significante flotante}

Los significantes vacíos y flotantes son términos cuya característica fundamental es su polisemia y su vaguedad a la hora de tener un significado unívoco y que, de hecho, pueden estar presentes en proyectos políticos dispares. Véanse por ejemplo términos como "patria" o "libertad", siempre al arbitrio en su significado del actor y del lugar discursivo desde el que se enuncia. "Los significantes vacíos son términos polisémicos que pueden inscribirse en proyectos políticos distintos -incluso opuestos- y en pugna." 44 De esa manera, para Laclau, "no es la pobreza de significados, sino al contrario, la polisemia, la que desarticula una estructura discursiva" 45 .

En efecto, es la ambigüedad de los términos como "pueblo", que no encarnan un significado literal, la que los hace tan moldeables a la hora de la disputa en el campo político

https://www.essex.ac.uk/centres/TheoStud/documents and files/pdf/Laclau\%20-

$\%$ 20philosophical $\% 20$ roots $\% 20$ of $\% 20$ discourse $\% 20$ theory.pdf

${ }^{39}$ Ibid.p. 6 (traducción mía)

40 Ibid.

${ }^{41}$ Errejón, op. cit.

42 Ibid. p. 254

${ }^{43}$ Howarth, op. cit. (2005), p. 49-50

44 Ana Soledad Montero: Significantes vacíos y disputas por el sentido en el discurso político: un enfoque argumentativo. IDENTID ADES, No. 3, Año 2, Diciembre, (2012), pp. 1-25, p. 2.

${ }^{45}$ Ernesto Laclau: "Estructura, historia y lo político", en Butler, J., Laclau, E., Žižek, S.: Contingencia, hegemonía, universalidad. Diálogos contemporáneos de la izquierda, Buenos Aires, FCE (2004). cit. en Ibid. p. 3 
discursivo. Por eso siempre se definen en oposición a otros términos -como "despotismo" en el caso del acta estudiada.

La diferencia entre significante vacío y flotante es la capacidad para ser o no puntos nodales que condicionen el resto de significados que devienen del contenido dado al significante vacío. Los puntos nodales del discurso serían aquellos términos privilegiados que en torno a él reúnen la definición de otros flotantes, por lo que esos puntos nodales siempre tendrán forma de significantes tendencialmente vacíos en su significado. Slavoj Žižek muestra un ejemplo:

\begin{abstract}
Cuando arropamos los significantes flotantes de Comunismo, por ejemplo, lucha de clases confiere una significación precisa y fija a todos los demás elementos: a democracia (la llamada democracia real opuesta a la democracia burguesa formal como forma legal de explotación); a feminismo (la explotación de las mujeres como resultado de la división clasista del trabajo); a ecologismo (la destrucción de los recursos naturales como consecuencia lógica de la producción capitalista orientada a la obtención de beneficio privado); al movimiento pacifista (el principal peligro para la paz es el agresivo imperialismo), y así... ${ }^{46}$
\end{abstract}

Así, los significantes vacíos serían los centrales y los flotantes los auxiliares, siendo los primeros los que concentran la capacidad de condicionar el significado del resto de significantes flotantes. En el caso analizado, el significante vacío será "independencia" (que crea una frontera con el monarca), siendo flotantes "desorden", "americanos", etc.

\title{
Huir del anacronismo: contextualismo e historia de los conceptos
}

\section{a. Contextualismo}

La historiografía dedicada al pensamiento político -y aquí incluimos teoría, historia y filosofía política- tradicionalmente ha interpretado los tratados o los textos partiendo de que su importancia tiene que ver con la grandeza de las visiones de los distintos autores. De este modo, las ideas de "los clásicos" serían universales ${ }^{47}$. Por tanto, son favorables o detractores de tal o cual idea universal, o van añadiendo progresivamente su parte para que el pensamiento se abra a nuevas formas. De esta manera, como dice Skinner ${ }^{48}$, se podría hacer una teorización primigenia sobre la división de poderes que se desplegase a lo largo de la historia desde el Imperio Romano. Esto se debe a que, como decíamos, habría ideas perennes que recorren la historia y que tendríamos que ir desentrañando a través de esos grandes pensadores.

Un error metodológico fundamental a evitar en este trabajo es dar por sentado la existencia de "ideas universales". De hacerlo, se estarían interpretando los textos desde el hoy y por tanto, aplicando criterios actuales al pasado; haciendo de nuestras propias interpretaciones presentes -y contingentes- algo universal en el tiempo y el espacio. Si partiésemos de la creencia en "ideas universales" sería fácil aceptar la posibilidad de trazar equivalencias entre el hoy y el ayer en cuanto al significado de las palabras y los enunciados ${ }^{49}$ de la declaración de independencia venezolana. A este trazo de equivalencias entre el presente y el pasado se le denomina "textualismo" en contraposición a "contextualismo".

Para solventar este posible error de anacronismo, el análisis de discurso aquí planteado necesitará entonces atender al contexto en el que es elaborado el texto elegido. Como se ha venido diciendo, las cosas toman sentido cuando tienen un significante y un significado. Las palabras no toman sentido por el mero hecho de existir, sino que lo hacen cuando nombran fenómenos de

\footnotetext{
46 Slavoj Zizek: The Sublime object of ideology, London, Verso (1989) cit. en Errejón, op. cit. (2012), p. 176

47 Javier Franzé: ¿Para qué sirven los clásicos? Cuadernos Hispanoamericanos, 633, septiembre (2005), p. 114-121.

${ }^{48}$ Quentin Skinner: Significado y comprensión en la historia de las ideas en Revista de Historia Intelectual, n 4 (2000), p. 149191.

49 Emilio Rabasa Gamboa: La escuela de Cambridge: historia del pensamiento político. Una búsqueda metodológica. Enclaves del pensamiento, año V, núm. 9, enero-junio (2011), pp. 157-180.
} 
percepción de las cosas. Así, lo fundamental para entender una palabra en toda su dimensión es hacer caso al contexto, siempre social, en el que se circunscribe ${ }^{50}$.

Partiendo de estas consideraciones, hay sobre todo dos aspectos metodológicos que vamos a criticar del textualismo y que intentaremos reconstruir desde una perspectiva contextualista. El primero está basado en la supuesta coherencia que, desde el textualismo, se le busca a todo texto; y el segundo aspecto sería el hecho de confundir la palabra con su significado ${ }^{51}$.

Tradicionalmente, el estudio del pensamiento ha buscado la coherencia entre los diferentes escritos de los autores o la ha buscado dentro de los textos, a pesar de que existan contradicciones en dichas obras. Se gira alrededor del texto buscando interpretaciones que añadan coherencia a lo que presumiblemente el autor quiso expresar. La premisa sería que se trata de escritos interpretables a través del mismo sentido actual de coherencia y/o no se contemplase la posibilidad de que la contradicción exista:

(...) la coherencia, o su falta, que se descubren con tanta ligereza, dejan de ser una relación histórica de ideas que realmente se hayan pensado alguna vez. La historia así escrita no se convierte en absoluto en una historia de las ideas, sino en abstracciones: una historia de pensamientos que en realidad nadie llegó a pensar nunca, en un nivel de coherencia que, de hecho, nadie alcanzó nunca. ${ }^{52}$

En consecuencia, el fundamento metodológico que guía este análisis es el del contexto, que es lo que nos permite no confundir la palabra con su significado una vez que, como nos recuerda Skinner, se acepte que "la noción de que cualquier 'idea' fija ha persistido, es espuria." 53

Es necesario situarse en la época y en el significado que los conceptos tenían para la gente que los escribía. La palabra y su significado deben ser analizados en su contexto. Siguiendo con el ejemplo de "independencia", según Fernández Sebastián ${ }^{54}$, éste era un vocablo que apenas se utilizaba y que empieza a llenarse de contenido político a finales del S.XVIII y va tomando notoria importancia en la Edad Contemporánea. Por tanto, su significado varió con el paso del tiempo y no tiene el mismo significado hoy que en aquéllos días. De hecho, como hemos visto, es imposible entenderlo puramente a través de autores si no hacemos caso del contexto en el que se encuadra el susodicho significante. Del mismo modo, ha habido distintos autores que en distintas épocas y hasta el día de hoy se preguntaron si la independencia ha sido "real" 55 . Sin embargo, una investigación que busque la coherencia entre "independencia" e "independencia realmente existente", sería una investigación sobre ideas o abstracciones que, en la práctica, nunca nadie llegó a pensar con ese nivel de coherencia.

\section{b. Historia de los conceptos}

Al margen de que la intención política de esas declaraciones sea construir una interpretación del mundo que ellos consideran como la sensata; y se construyan dos bandos enfrentados (uno con derechos y otro sin ellos), necesitamos saber cuáles pueden ser los significantes que en aquella época podían tener potencia a la hora de construir esa realidad de dos bloques enfrentados. Para poder conocer esto, hemos elegido la metodología de la Historia de los conceptos de Reinhart Kosselleck:

Las teorías actualmente en boga que reducen la realidad al lenguaje olvidan que todo lenguaje tiene siempre dos caras. Por un lado, el lenguaje es receptivo y registra lo que sucede fuera de sí mismo, descubriendo aquello

\footnotetext{
${ }^{50}$ Howarth, op. cit. (1995)

51 Skinner, op. cit.

52 Ibid.p. 162

53 Ibid. p. 177

${ }^{54}$ Javier Fdez. Sebastián "La independencia de España y otras independencias. La transformación radical de un concepto en la crisis del mundo hispano", en Alfredo Ávila, Jordana Dym y Erika Pani: Las Declaraciones de Independencia: los textos fundamentales de las independencias americanas, El Colegio de México y Universidad Autónoma de México (2013), pp. 41-81.

55 José Carlos Mariátegui: 7 ensayos de interpretación de la realidad peruana, Biblioteca Ayacucho (2007); Milcíades Peña: Masas, Caudillos Y Elites La Dependencia Argentina De Yrigoyen A Perón, Buenos Aires, Fichas (1973); Julio Sevares: ¿Cooperación SurSur o dependencia a la vieja usanza? en NUEV A SOCIED AD, No 207 (2007), 11-22.
} 
que se le impone sin ser en sí mismo lingüístico, a saber: el mundo, tal y como se nos presenta pre-lingüísticamente (y no-lingüísticamente). Por otro lado, el lenguaje, en su función activa, asimila (einverwandelt sich) todos estos contenidos y estados de cosas (Gegebenheiten) extralingüísticos ${ }^{56}$.

En relación al Acta de Independencia del país analizado, esto nos pone sobre aviso de que el texto contenido en ese documento histórico no es una mera declaración retórica, sino que hace pública una interpretación de la realidad política enfrentada a otra; la cual, a su vez, tiene su propia interpretación de esa misma realidad, ya que "la propia realidad no se deja reducir a su significado y forma lingüística (Gestaltung) pero sin tales contribuciones lingüísticas probablemente no habría realidad, al menos para nosotros." 57

Por ejemplo, en la declaración de la que se ocupa este trabajo, aparece la palabra "libertad". La libertad es uno de esos significantes que no es lo mismo pronunciarlos en aquella época que hoy en día. Hoy en día es un término en disputa por distintas ideologías y en aquella época también, pero las ideologías que disputan por el término no son las mismas en el S.XIX que ahora. Por eso sería contraproducente desde la voluntad de rigurosidad científica interpretar "libertad" como ahora; habría, por tanto, que darle un recorrido histórico al concepto y entender ese significante en su contexto, algo determinante para conocer su significado.

Durante el Antiguo Régimen no se entendía la "libertad" como singular, sino como plural, las "libertades". Lo que se pretende hablando de "libertad" es darle un valor universal en contraposición con las "libertades" corporativas propias del Antiguo Régimen y de cada uno de los estamentos. La "libertad" es una metáfora que se vuelve un concepto cargado de expectativas hacia un futuro en el que todos serían iguales y todos tendrían las mismas libertades ${ }^{58}$.

Conceptos centrales: "independencia" y "América / americanos"

\section{Independencia}

El concepto de "independencia" comienza a resignificarse a partir de un momento de conflicto en el que, como dice Koselleck, hay palabras centrales que empiezan a disputarse y a tomar significados diversos según quien las diga.

En la Constitución de Cádiz de 1812 durante la invasión napoleónica de España se señala que "la Nación española es libre e independiente, y no es ni puede ser patrimonio de ninguna familia ni persona"59. Aquí la palabra "independiente" remite al hecho de que España estaba conquistada por una fuerza exterior y se disputaba una Guerra de Independencia, tal y como se le dio en llamar. Era una guerra para recuperar la soberanía con respecto a una potencia extranjera. Sin embargo, el hecho de que el artículo 2 la Constitución diga al final que la nación no puede ser "patrimonio de ninguna familia ni persona" está afirmando que la independencia no solamente puede ser concebida con respecto al resto de naciones, sino que debe ser concebida como la independencia con respecto al propio monarca. Esto conduce a un debate sobre la soberanía, que ya no residiría en el soberano (o no completamente). Si la independiente es la nación, es porque, a la vez, esta pasaría a ser el sujeto soberano.

Finalmente, la guerra no resituó la soberanía ni la independencia; sino que la mantuvo en su sentido tradicional, convirtiendo la independencia en una recuperación de la soberanía con respecto al extranjero y conservando la figura de la monarquía tradicionalista encarnada en la persona de Fernando VII. Los medios tradicionalistas no escatimaron esfuerzos en resignificar la palabra incluso

\footnotetext{
${ }_{56}$ Reinhart Koselleck: "Historia de los conceptos y conceptos de historia" en Ayer no 53 (2004), 27-45.

p. 30

${ }^{57}$ Ibid.

${ }^{58}$ Ibid.

${ }^{59}$ Fdez. Sebastián op. cit. (2013) p. 60
} 
en los propios términos tradicionalistas; exponiendo que la independencia de España era la independencia del monarca "cautivo" en Francia ${ }^{60}$.

La abdicación de los Borbones en Bayona en favor del Imperio napoleónico había producido un vacío de soberanía que precisamente había sido aprovechado por los constitucionalistas gaditanos para, como se decía, resituar la soberanía y la independencia. En América, a este vacío de soberanía se reaccionó con la formación de Juntas que depusieron a las autoridades metropolitanas (virreyes y capitanes generales) para formar luego congresos elegidos mediante votación. Estos congresos declararon la independencia posteriormente, ya que al principio se formaron para defender la soberanía de Fernando VII. No hay que olvidar que el virrey era un cargo que hacía las veces de rey en América, por lo que después de la abdicación en Bayona, su legitimidad era relativa a la hora de garantizar la autonomía con respecto a los franceses, dado que el rey había renunciado a sus derechos dinásticos.

Esta independencia no tenía un sentido distinto para los congresistas americanos. Sin embargo, en las colonias fueron capaces de resituar el término, y se refería a la independencia del pueblo (de los americanos) con respecto a esa dependencia que se tenía de la monarquía; única institución política dotada de independencia y soberanía hasta aquel momento. Significaba no sólo la emancipación de la metrópolis como tal, sino la independencia de toda autoridad ajena al pueblo americano. Frente a las sociedades monárquicas basadas en una dependencia orgánica entre partes con el rey como cabeza del cuerpo, se buscaba ahora la independencia de los pueblos ${ }^{61}$.

\section{América / americanos}

Prestar atención al concepto central de "América" o "los americanos" y el significado que tenían en la época no significa que, por el hecho de que dicha identidad existiese, tuviese que desembocar en un proceso de independencia. Tampoco significa que estuviese ligada a una reclamación nacionalista en el sentido moderno del término.

Las singularidades en las que se fundamentó dicha identidad americana no tenían especialmente un contenido esencialista cultural o antropológico. Precisamente, esas singularidades culturales, legales, jurisdiccionales, etc, eran perfectamente complementarias con las concepciones tradicionalistas de la Monarquía de Las Españas. Estas diferencias estaban incluso incrustadas en la misma concepción de los diferentes reinos de la Península y fue la concepción hegemónica de la idea de España de manera prolongada en el tiempo ${ }^{62}$. En otras palabras, la "protonacionalidad española" - tomando prestado el término de Hobsbawn ${ }^{63}$ - no era cuestionada como tal en América, esto estaba perfectamente neutralizado discursivamente por el peso del tradicionalismo. La disputa discursivo-conceptual central consistió en la apropiación y resignificación de la identidad difusa de "americano", que nada tenía que ver con considerarse extranjero en la comunidad política propia.

El significante "América" o "americano" tuvo una utilización más o menos constante en los períodos anteriores a la independencia y se utilizó con mayor énfasis según se aproximaba la época independentista. No fue casual: durante el período colonial se utilizaba este gentilicio para nombrar a los indígenas. Para los criollos, por ejemplo, se utilizaba la expresión "español americano" ${ }^{4}$. El motivo de que esta palabra fuese utilizada durante una contienda política significa que representaba una identidad que unos u otros pretendieron arrogarse tanto para defender las Españas y sus distintos reinos -tal y como tradicionalmente se había utilizado el término América-; como para atacar a este mismo concepto en favor de la independencia de América. Ya fuese de Sud América, de la América Meridional o la de aquella célebre frase de Bolívar: "Para nosotros, la Patria es América".

\footnotetext{
${ }^{60}$ Ibid. p. 61

${ }^{61}$ François-Xavier Guerra: Modernidad e independencias: ensayos sobre las revoluciones hispánicas. Madrid, MAPFRE (1992).

${ }^{62}$ Javier Fdez. Sebastián: España, monarquía y nación. Cuatro concepciones de la comunidad política española entre el Antiguo Régimen y la Revolución liberal en Studia Historica-Historia Contemporánea, Vol. XII (1994), pp. 45-74.

${ }^{63}$ Eric Hobsbawn: Naciones y nacionalismo desde 1780, Crítica (2000).

${ }^{64}$ Joao Feres Júnior: "El concepto de América, ¿concepto básico o contraconcepto?”, en Javier Fernández Sebastián (director): Diccionario político y social del mundo iberoamericano: La era de las revoluciones, 1750-1850. Iberconceptos-I, Madrid, Centro de Estudios Políticos y Constitucionales (2015), pp. 51-67
} 
A pesar de la cada vez mayor utilización del término "América", tras los procesos de independencia entra en franca decadencia y progresivamente pasan a ser utilizados los gentilicios de cada nuevo estado: venezolano, peruano, etc. Esta decadencia se debió a que la palabra que expresaba una identidad americana perdió su "función" política una vez que se formaron los estados. A partir de ese momento se volvió imprescindible construir estados-nación soberanos. De hecho, Guerra ${ }^{65}$ afirma que la palabra "nación" no aparece en ningún escrito anterior a la independencia. En el mismo sentido, vale la pena recordar lo que ya fue mencionado anteriormente: los hispanoamericanos nunca se refirieron a su proceso de independencia como una "guerra", sino como una revolución; un cambio de régimen ${ }^{66}$.

De esta manera, se puede concluir que el significado de "independencia" estaba muy ligado a la idea de que era necesaria, para el cambio de régimen, la formación de un pueblo americano soberano en oposición al rey; formar un estado y, posteriormente, convertir al "americano" en nacional. El trinomio fue el siguiente: independencia de los americanos con respecto al rey para formar un estado capaz de articular una soberanía nacional.

\section{Análisis del Acta de Independencia de las Provincias Unidas de Venezuela}

\section{De las Juntas a la Declaración de Independencia de 1811}

Tras la victoria napoleónica contra los ejércitos españoles en la Península, en 1808 tuvieron lugar las Abdicaciones de Bayona, donde Carlos IV y su hijo Fernando VII renunciaron a la Corona Española y reconocieron como rey legítimo al hermano de Napoleón, José I, lo que provocó un vacío de poder en las colonias españolas.

Los virreyes y capitanes generales ejercían su gobierno en nombre del rey y del mismo monarca emanaba su poder. Pero el monarca José I no fue reconocido en América y, a imitación de las Juntas españolas, se formaron en las ciudades americanas órganos -llamados también Juntas- para defender los derechos al trono de Fernando VII. Sin embargo, la Junta Central en España y el gobierno regente del Congreso de Cádiz no las reconocieron, por lo que declararon sus Juntas independientes de la peninsular. Seguidamente, derrocaron a los virreyes y capitanes generales para tomar el vacío de soberanía que se había producido cuando: por un lado, Fernando VII abdicó y las autoridades coloniales se transformaron en leales a José I; y cuando, por otro lado, las autoridades regentes metropolitanas no reconocieron los movimientos de las juntas americanas. A la vez, los americanos obtuvieron una muy pequeña representación en las Cortes gaditanas. En Caracas, este proceso se produjo en 1810, y conservó la finalidad de proteger los derechos reales de Fernando VII.

La Junta de Caracas convocará, después de un año (1811), su propio congreso paralelo al de Cádiz, donde a los americanos les parecía que tenían una representación poco acorde con su importancia. Esta convocatoria se siguió haciendo en nombre del propio Fernando VII y de la conservación de sus derechos a la corona, imitando a su metrópoli. Por tanto, durante todo este período, no había una impugnación a la totalidad del régimen existente, a la majestas, que era el mandato del propio rey; sino que la impugnación era relativa a la administratio del monarca, es decir, al cómo se estaba ejerciendo la majestas ${ }^{67}$. En otras palabras, existían una serie de demandas por parte de muchos grupos sociales. Exigencia de igualdad política y social, acceso a la riqueza... Tal y como nos muestra Alfaro Pareja:

(...) la diatriba se complejiza, exacerba y dinamiza con la participación de sectores sociales cuyas expectativas, necesidades e intereses no siempre tuvieron relación directa con el objetivo político de la emancipación (...). Los esclavos deseaban libertad, los pardos, canarios y sectores medios ansiaban igualdad; los criollos mantuanos el poder político, las regiones querían administrar el poder en su

\footnotetext{
${ }^{65}$ Guerra op.cit. p. 159

${ }^{66}$ Feres Junior: op. cit.

${ }^{67}$ José María Portillo: "Independencia constituyente". En Ávila, Alfredo; Dym, Jordana; Pani, Erika: Las Declaraciones de Independencia: los textos fundamentales de las independencias americanas, El Colegio de México y Universidad Autónoma de México (2013) pp. 479-495, p. 485
} 
jurisdicción. El proceso de Independencia fue un gran conjugador de estas iniciativas $^{68}$

No obstante, no había un cuestionamiento del sistema monárquico como tal. Por lo menos no hasta que grupos de presión como la Sociedad Patriótica comenzaron a agrupar a grandes sectores de la población a su alrededor a favor de la independencia ${ }^{69}$. De ella formaban parte personajes como Francisco Miranda (futuro presidente) o Simón Bolívar.

Así, en ese mismo año, Bolívar dio un discurso en el Congreso animando a declarar la independencia. El dilema planteado por la Sociedad Patriótica en el Congreso se dirimió con una apabullante mayoría a favor de la declaración de independencia. Solo un diputado votó en contra alegando que a él no se le había convocado en el Congreso para esa finalidad, sino para defender los derechos del monarca legítimo. Se formó así la Primera República, que duró solamente un año (18111812).

La experiencia fue desastrosa. Venezuela dependía de las exportaciones hacia mercados hispanos que le fueron bloqueados. Los precios de los productos importados fueron encareciéndose y se emitió papel moneda que provocó una inflación galopante. De ahí que cuando los españoles recuperaron Caracas fueran recibidos con enorme aceptación. Pero la caída de Caracas no significó el control del territorio por parte de los españoles, ya que grandes destacamentos de esclavos se habían rebelado en los llanos del país ${ }^{70}$.

El advenimiento de la Segunda República tuvo lugar en 1813 cuando Simón Bolívar culminó la Campaña Admirable entrando en Caracas. Pero apareció un actor ineludible para la caída de la Segunda República en 1814: José Tomás BovesEste había aprovechado la movilización esclava de los llanos para convencerlos de que no debían apoyar a los independentistas ya que los mantuanos (sus dueños) lo eran. La desestabilización causada por los grandes ejércitos que llegó a controlar provocó el debilitamiento de la República y fue causa fundamental de su caída.

Finalmente, Venezuela lograría su independencia de manera conjunta con los actuales estados de Colombia, Ecuador y Panamá, siendo parte de la Gran Colombia en el Congreso de Angostura de 1819.

\section{El liberalismo como ideología de la independencia de Venezuela}

Durante la contextualización de la independencia de Venezuela continuamos narrando los hechos históricos acaecidos luego de la propia declaración porque para ver la ideología que se apropió de las palabras allí escritas nos hace falta irnos a 1819 y a la formación de la Gran Colombia, debido a que los anteriores períodos de independencia son demasiado cortos como para justificar con argumentos sólidos la ideología de los actores que luego ejercieron el poder del estado.

Desde la caída de la Segunda República hasta el nacimiento de la Gran Colombia en el Congreso de Angostura, se sucedieron las campañas militares con el objetivo de hacerse con el control del territorio. Tras la campaña de Boves, en 1815 los realistas lograron derrotar a los independentistas, provocando el exilio de Bolívar a Jamaica desde donde escribió su famosa carta — Carta de Jamaicaen la que exponía los motivos para la declaración de la independencia y la necesidad de liberar a todo el continente hispanoamericano. Tras esto, Bolívar desembarcó en Isla Margarita y se reunió la Asamblea que lo nombró Comandante en Jefe del ejército. Además, se declaró la Tercera República, que se prolongó durante la última fase de la guerra hasta la victoria definitiva y la convocatoria del Congreso de Angostura (1819) fundador de la Gran Colombia.

El rigor de la exposición no se verá dañado por esta translación de ocho años entre 1811 fecha de la declaración analizada - y 1819, ya que fueron los mismos integrantes del Congreso de

\footnotetext{
${ }^{68}$ Francisco Alfaro Pareja: "El horizonte de las ilusiones populares: La Independencia de Venezuela y los conflictos no resueltos" en Historia Caribe, vol. IX no 24 Enero-Junio (2014), pp. 63-87, p. 71

${ }^{69}$ Manuel Lucena Salmoral: "El Siglo XIX: La utopía de libertad, orden y progreso" en Manuel Lucena Salmoral (coord.): Historia de Iberoamérica, Tomo III Historia Contemporánea, Madrid, Cátedra (1988).

${ }^{70}$ Ibid.
} 
Angostura los que reconocieron la legalidad de las Provincias Unidas de Venezuela nacida en 1811, y se reivindicó como acto de soberanía de un pueblo ${ }^{71}$.

Para justificar el ideal liberal que inspiró la declaración de independencia venezolana se hará una breve comparación con el ideal republicanista que guio la de los Estados Unidos. Esta idea se basa en el significado que tenía el término República/republicano en aquella época en Hispanoamérica; y en el artículo ya citado de Belin y Vázquez.

En la Hispanoamérica del S. XIX, la palabra "república" o "republicano" no hacía referencia a un ideario político que fundamentase una ideología política como tal, en contraposición al caso norteamericano. Se entendía que la república era tendiente a "un sentir opuesto al ideario monárquico"72, ya que el concepto "monarquía" tenía connotaciones patrimoniales que no tienen más finalidad que la conveniencia propia y no la de la cosa pública, es decir, era contraria al bien común. De esta manera, eran posibles formulaciones mixtas que proponían monarquías republicanas. En otras palabras, monarquías que ejerciesen el buen gobierno ${ }^{73}$.

La imagen de lo republicano se remitía a los valores y virtudes propias de la Antigüedad republicana romana, que se entendían como algo positivo en cuanto a las actitudes que debería tener alguien dedicado a la cosa pública. Pero la transformación de la expresión en una realidad institucional no dejaba de considerarse un anacronismo utópico: "era una cultura política plena, pero una forma política vacía" "74. Esto no sucedió en las Trece Colonias, donde por ejemplo Thomas Paine logró regenerar una idea obsoleta de modo que pudiese representar un horizonte y un proyecto político de cara al futuro ${ }^{75}$. La autorrealización del individuo se daba a través del espacio público -que es donde realmente se es libre-, entendido como el lugar verdaderamente político (republicano) que debía ser protegido de otros intereses privados y al cual debía estar conectado por un mero sentimiento de civismo.

Si estos eran los presupuestos ideológicos de los que partía la Declaración de Independencia de los Estados Unidos, los de Venezuela serían distintos. La independencia se concibe como la independencia de la misma comunidad política. Esta tendría unos intereses comunes que habría que defender cuando se participaba en política. Por otro lado, se tenía la concepción de que el hombre se hacía libre en su ámbito privado a través de su capacidad para aprender y de la razón. Lo cual estaba muy ligado a la capacidad material que se pudiese tener para permitirse poder ejercer dicha libertad, es decir, a ser o no propietario ${ }^{76}$.

Como vemos, si en la ideología republicana el hombre se hace libre mientras participa en la política por amor cívico, en la ideología liberal el individuo participa en política en base una libertad previamente adquirida por la razón, condición sine qua non para su participación en política:

Si en los varones propietarios, los 'vicios privados' para alcanzar las 'virtudes públicas’ debían ser controlados al servicio de una comunidad racional y ordenada, para los excluidos del estado de naturaleza los 'malos vicios y las bajas pasiones' se controlaban por medio de las prácticas de la 'represión'. En ambos casos, el interés económico privaba como 'instrumento dominante mediante el cual se podían subyugar las pasiones ${ }^{37}$

Si a esta concepción en la que la virtud pública emana de la virtud privada, de la cual están excluidos los no-libres, añadimos la creencia en el hecho de que la independencia y cambio de régimen es una concepción colectiva y no individual, se puede concluir que el elitismo liberal fue la ideología que inspiró la Declaración de Independencia de las Provincias Unidas de Venezuela.

\footnotetext{
${ }^{71}$ M. Belin, y V. Vázquez: "Independencia y estado-nación en Venezuela desde los regímenes de la gubernamentabilidad" en Documentos de trabajo IELAT, n 17 (2010), 24-48.

${ }^{72}$ Georges Lomné: De la República y otras repúblicas: La regeneración de un concepto. En Javier Fernández Sebastián (director): Diccionario politico y social del mundo iberoamericano: La era de las revoluciones, 1750-1850. Iberconceptos-I, Madrid, Centro de Estudios Políticos y Constitucionales (2015), pp. 1253-1369, p. 1277

73 Ibid.

${ }^{74}$ Ibid. p. 279

75 Ibid.

${ }^{76}$ Belin y Vázquez: op. cit.

${ }^{77}$ Ibid. p. 31
} 


\section{Análisis de discurso de la Declaración de Independencia de las Provincias Unidas de Venezuela}

\section{La interpretación de los hechos que construye la realidad independentista}

La estructura temática del acta podría resumirse en una crítica al gobierno por haber abandonado la obligación del propio rey de hacer cumplir las leyes. En este apartado se critica tanto al gobierno napoleónico como al monarca español Fernando VII y a las Cortes de Cádiz. Estos eran los tres responsables de ese vacío de soberanía que los americanos, sin desearlo, se han visto en la obligación de ocupar. Se continúa justificando las bondades de la independencia y la necesidad de declararla. Y finalmente se declara la capacidad de Venezuela como estado para valerse de los instrumentos necesarios para defenderse en la guerra y trazar relaciones comerciales.

En esta acta, también se construye una realidad que hace referencia a los hechos acontecidos inmediatamente antes a la declaración, olvidando "generosamente la larga serie de males, agravios y privaciones que el derecho funesto de conquista ha causado (...) corriendo un velo sobre 300 años de dominación española" (VVAA, 2013) ${ }^{78}$.

La interpretación fundamental se centrará en el vacío de poder que provocaron los españoles en América. Un monarca tenía la responsabilidad de proteger y gobernar bien todos sus territorios, pero la había abandonado, "dejándola sin el amparo y garantía de las leyes". De hecho, el acta empieza dejando claro que, con las abdicaciones de Bayona, de facto los americanos ya habían asumido la soberanía y el gobierno de sí mismos antes de declarar la independencia:

En consecuencia, de la jornada de Bayona y la ocupación del trono español por la conquista y sucesión de otra nueva dinastía constituida sin nuestro consentimiento, queremos, antes de usar de los derechos de que nos tuvo privados la fuerza, por más de tres siglos, y nos ha restituido el orden político de los acontecimientos humanos, patentizar al universo las razones que han emanado de estos mismos acontecimientos y autorizan el libre uso que vamos a hacer de nuestra soberanía.

En este contexto, los americanos que controlaron de facto el gobierno se mostraron generosos y defendieron los derechos de Fernando VII al trono de España, pese a que éste no cumplía con sus obligaciones: "Las sesiones y abdicaciones de Bayona, las jornadas del Escorial y de Aranjuez, y las órdenes del lugarteniente duque de Berg, a la América, debieron poner en uso los derechos que hasta entonces habían sacrificado los americanos a la unidad e integridad de la nación española."

Este respeto por la monarquía se verá frustrado no por deseo de los americanos, sino por las acciones de mal gobierno que ejercieron en primer lugar los Borbones, cediendo sus responsabilidades a un rey extranjero. En segundo lugar, porque las Cortes de Cádiz no otorgaron la suficiente representación a los americanos y declaró en rebeldía a las autoridades que en América se levantaron para precisamente hacer lo mismo que estaban haciendo ellos en la metrópolis. Los Borbones erraron cuando:

(...) concurrieron a las inválidas estipulaciones de Bayona, abandonando el territorio español, contra la voluntad de los pueblos, faltaron, despreciaron y hollaron el deber sagrado que contrajeron con los españoles de ambos mundos (...); por esta conducta quedaron inhábiles e incapaces de gobernar a un pueblo libre, a quien entregaron como un rebaño de esclavos.

Y no solo eso, sino que los redactores especularon con la posibilidad de que Fernando VII no estuviese realmente dispuesto a volver para hacerse cargo de sus responsabilidades, ya que “(...)

\footnotetext{
${ }^{78}$ Se cita aquí el acta de independencia recogida en Alfredo Ávila; Jordana Dym y Erika Pani: Las Declaraciones de Independencia: los textos fundamentales de las independencias americanas, El Colegio de México y Universidad Autónoma de México (2013) p. 521524. Y citada de ahora en adelante únicamente con comillas.
} 
a las relaciones de la fuerza que le ligaban con el Emperador de los franceses ha añadido los vínculos de sangre y amistad".

Por su parte, y según la realidad construida en el acta, los franceses habían llegado a España con promesas de libertad e igualdad, pero en realidad se estaban arrogando una representación nacional que no les pertenecía. De hecho, era culpa de los mismos franceses que los americanos creyesen que Fernando VII volvería para gobernar, así no podrían valerse de instrumentos suficientes para mantenerse libres: “( ...) y contra sus mismos principios, sostuvieron entre nosotros la ilusión a favor de Fernando, para devorarnos y vejarnos impunemente (...)".

Por último, la maniobra para atacar al Congreso de Cádiz gira en torno al rechazo a lo que sus "hermanos" americanos estaban practicando políticamente en su territorio, que era lo mismo que hacían ellos en España. Pero en el caso americano se le llamó "perfidia e ingratitud". El motivo de esto, según los venezolanos, era que, con la reacción americana a la invasión francesa, se les caerá por tierra el proyecto de tener el monopolio del poder en nombre de un rey que no existía:

Luego que se disolvieron, sustituyeron y destruyeron entre sí las varias formas de gobierno de España, y que la ley imperiosa de la necesidad dictó a Venezuela el conservarse a sí misma para ventilar y conservar los derechos de su rey y ofrecer un asilo a sus hermanos de Europa contra los males que les amenazaban, se desconoció toda su anterior conducta, se variaron los principios, y se llamó insurrección, perfidia e ingratitud, a lo mismo que sirvió de norma a los gobiernos de España, porque ya se les cerraba la puerta al monopolio de administración que querían perpetuar a nombre de un rey imaginario.

En cuanto a los agravios cometidos por las Cortes de Cádiz, aquellos consistieron en haber declarado en rebeldía a las Juntas y Congresos americanos. Así como desoír las demandas que buscaban una representación americana en Cortes acorde con sus estatus, tamaño y población. Contrariamente a eso, se encontraron con una mezquina representación aceptada por obligación:

\begin{abstract}
A pesar de nuestras protestas, de nuestra moderación, de nuestra generosidad, y de la inviolabilidad de nuestros principios (...) se nos declara en estado de rebelión, se nos bloquea (...). Sin hacer el menor aprecio de nuestras razones, sin presentarlas al imparcial juicio del mundo, y sin otros jueces que nuestros enemigos, se nos condena a una dolorosa incomunicación con nuestros hermanos; y para añadir el desprecio a la calumnia se nos nombran apoderados, contra nuestra expresa voluntad, para que en sus Cortes dispongan arbitrariamente de nuestros intereses bajo el influjo y la fuerza de nuestros enemigos. Para sofocar y anonadar los efectos de nuestra representación, cuando se vieron obligados a concedérnosla, nos sometieron a una tarifa mezquina y diminuta y sujetaron a la voz pasiva de los ayuntamientos, degradados por el despotismo de los gobernadores, la forma de la elección; lo que era un insulto a nuestra sencillez y buena fe, más bien que una consideración a nuestra incontestable importancia política.
\end{abstract}

Ante esta situación de abandono por parte de su metrópolis, los americanos habían tenido que asumir el control de sus propios gobiernos sin ningún tipo de ayuda; todo lo contrario, con la oposición de las autoridades peninsulares. Habían tenido que enfrentarse y desconectarse de sus propios hermanos peninsulares, una vez que, "con esta atroz política, han logrado hacer a nuestros hermanos insensibles a nuestras desgracias, armarlos contra nosotros, borrar de ellos las dulces impresiones de la amistad y de la consanguinidad, y convertir en enemigos una parte de nuestra gran familia."

Los declarantes del acta plantean una realidad en la que se soportaron los agravios por principios y generosidad. Pero tras tres años de "predecible desorden", la situación se habría vuelto intolerable si no hubiesen intervenido los propios americanos dotándose a sí mismos de instituciones capaces de mantener la "seguridad y felicidad de su país".

De este modo, de nuevo se plantea un arrinconamiento de las autoridades legítimas coloniales por parte de las autoridades metropolitanas, que fuerzan a las primeras a declarar una 
independencia para cumplir las demandas que el pueblo tenía. En el acta, las referencias a las demandas populares aparecen al principio de la declaración:

(...) olvidamos generosamente la larga serie de males, agravios y privaciones que el derecho funesto de conquista ha causado indistintamente a todos los descendientes de los descubridores, conquistadores y pobladores de estos países, hechos de peor condición, por la misma razón que debía favorecerlos (...).

Lo que los independentistas procuraban era ganarse el favor de todos aquellos que hacían demandas de tipo social, económico o político. Como investigó Alfaro Pareja: los esclavos demandaban libertad, los criollos querían el poder político, los pardos mayor igualdad, etc. La independencia se transformó y dejó de ser una opción política como cualquier otra para pasar a ser la opción de sentido común de los americanos, ya que sus demandas no cabían dentro del sistema político en el que vivían y era necesario cambiarlo.

\section{El "desorden" y "América/americanos" como frontera}

Esta identidad popular, la de "los americanos", se construye a través de una fuerte oposición entre estos últimos y los peninsulares. Estas fronteras se crean, sobre todo, a partir de dos significantes: el "desorden" y la identidad "americana".

En este contexto, el "desorden" se presenta como un significante flotante, en el sentido de que un bando acusa a otro de provocar desorden y viceversa. Los independentistas acusaban al rey, a los franceses y a las Cortes de Cádiz de haber sembrado el desorden abandonando sus obligaciones de gobernar bien. Este desorden solamente fue salvado por los propios americanos que tomaron las riendas del gobierno no por gusto, sino porque de lo contrario se avecinaría el "desorden (...) [y seríamos] conducidos a la horrorosa suerte que vamos a apartar (...).”

Sin embargo, por su parte, la metrópolis argumentó que las juntas americanas debían hacer caso de la Junta Central como cualquier otra junta del territorio español. Y cuando los venezolanos formaron su propio Congreso, es lógico que los metropolitanos de Cádiz pensasen que el único organismo legítimo era el suyo porque eran los regentes, y que, por tanto, le debían lealtad al ser ellos los representantes del rey Fernando. En otras palabras, para Cádiz también era perfectamente plausible argumentar que el desorden estaba siendo causado por los propios americanos.

Los independentistas construyeron ese desorden uniendo tres elementos para cada uno de sus adversarios políticos: el rey Fernando se había comportado como un tirano al haber preferido cuidar su propia vida y no complacer los deseos de un pueblo que lo reclamaba; el rey francés era ilegítimo porque era extranjero, una imposición del emperador francés que no era reconocida por el pueblo; y por último, las Cortes de Cádiz se habían comportado de manera mezquina al haber declarado ilegales los movimientos independentistas y al haberles otorgado, solo por obligación, una nimia representación en la Cámara: "Este desorden ha aumentado los males de la América, inutilizándole los recursos y reclamaciones, y autorizando la impunidad de los gobernantes de España para insultar y oprimir esta parte de la nación, dejándola sin el amparo y garantía de las leyes."

Con respecto a Fernando, se dice de él que dejó de ser monarca para ser tirano. Un monarca se transforma en tirano cuando deja de mirar por el interés general y pasa a procurar el interés propio: “(...) un rey que había apreciado más su propia existencia que la dignidad de la nación que gobernaba (...) por esta razón quedaron inhábiles o incapaces de gobernar a un pueblo libre a quien entregaron como un rebaño de esclavos".

Los franceses eran extranjeros e invasores, por lo que la frontera se trazó a través de esas dos cosas: Los intrusos gobiernos que se abrogaron la representación nacional aprovecharon pérfidamente las disposiciones que la buena fe, la distancia, la opresión y la ignorancia daban a los americanos contra la nueva dinastía que se introdujo en España por la fuerza (...). Con el Congreso de Cádiz la frontera se crea a través del despotismo del que hace gala en su trato hacia América:

(...) han procurado los gobiernos de España desacreditar todos nuestros esfuerzos declarando criminales y sellando con la infamia, el cadalso y la 
confiscación, todas las tentativas que, en diversas épocas, han hecho algunos americanos para la felicidad de su país, como lo fue la que últimamente nos dictó la propia seguridad.

Por eso era necesario declarar la "absoluta independencia de él (anterior orden) y de toda dominación extraña”. Obsérvese aquí como se hace referencia a la independencia con respecto al anterior orden. Esto nos habla de cómo los venezolanos concebían la independencia del rey a modo de cambio de régimen político. Cualquier cambio de régimen entienden que pasa por romper con la garantía de unión de los distintos pueblos que forman las Españas, que es precisamente la monarquía. Esta concepción de la monarquía rectora que está obligada al buen gobierno -y por tanto pacta con su pueblo-, y que es garante de unidad territorial, será muy importante para entender de nuevo que los hispanoamericanos tenían una identidad como "americanos" dentro de lo que venía a concebirse como el Reino de España. Ahora, ese pueblo americano resituaba la soberanía en sí mismo, y eso era lo que le hacía independiente.

Esta identidad americana se creó a través de tres palabras, "América", "americanos" y "nosotros". Es decir, los redactores se arrogan la capacidad de representar al pueblo americano, pero también de decidir quién es, o no es, parte legítima de ese pueblo. La palabra "América" o "americanos" aparece hasta nueve veces en el acta contando el título, y la palabra "nosotros" aparece diez. Si al "nosotros" le sumamos también el posesivo de primera persona del plural nuestro/nuestra- resultará que aparece siempre ligada a características positivas: nuestra moderación, generosidad, buena fe, principios inviolables, sencillez... En definitiva, se trata de un gran significante vacío que es el mismo que "América/americanos". Del mismo modo, la palabra "pueblo" o "pueblos" aparece en seis ocasiones. La mayoría de veces ligada a características como "virtuoso", "libre"...; o también aparecerá ligada a la "voluntad de los pueblos".

Sin embargo, también se habla de quien no forma parte del este pueblo. Se afirma, en una parte del texto, con que los metropolitanos envían agentes metropolitanos para "amotinarnos unos contra otros”. O también se dice:

(...) declaramos como amigos nuestros, compañeros de nuestra suerte, y participes de nuestra felicidad, a los que, unidos con nosotros por los vínculos de la sangre, la lengua y la religión, han sufrido los mismos males en el anterior orden; siempre que, reconociendo nuestra absoluta independencia de él y de toda otra dominación extraña, nos ayuden a sostenerla con su vida, su fortuna y su opinión, declarándolos y reconociéndolos (como a todas las demás naciones) en guerra enemigos, y en paz amigos, hermanos y compatriotas.

Es cierto que se hace referencia a los españoles, pero no deja de ser igualmente cierto que mediante este discurso se traza una equivalencia entre "unionista" y "adversario".

\section{Conclusiones}

En este trabajo se explicó la teoría del populismo de Laclau, preguntándose si valdría para interpretar fenómenos distintos a los movimientos políticos del populismo clásico, tal y como el propio Laclau se anima a proponer. Fue seleccionado como documento de análisis de esta posibilidad una declaración de independencia, la de Venezuela. Por tratarse de un documento histórico del siglo XIX fue necesario tomar una serie de precauciones metodológicas al respecto para huir del anacronismo y conocer el significado de las palabras en aquella época; así como la explicación de los conceptos clave que son utilizados para el análisis de discurso. Finalmente se pasó al análisis del documento en cuestión y se obtuvieron resultados satisfactorios.

Efectivamente, ciñéndose únicamente al documento, y no al proceso de independencia en su conjunto, se puede concluir que el Acta de Independencia de las Provincias Unidas de Venezuela contiene un discurso que Laclau denominaría como populista. "Los americanos" construyen una realidad política según la cual "el rey-tirano" y el "despotismo" oprimen al "pueblo" americano, generan "desorden" y se ve forzado a declararse "independiente" del monarca. 
En conclusión, tras este estudio, se puede afirmar que la teoría de Laclau, siempre y cuando se tomen las precauciones metodológicas necesarias, puede servir para interpretar distintos fenómenos políticos históricos, y no solo los movimientos del populismo clásico o fenómenos políticos que se podrían caracterizar simplemente bajo la etiqueta de "demagógicos", "antiliberales" o "irracionales".

\section{BIBLIOGRAFÍA}

- Ana Soledad Montero: Significantes vacíos y disputas por el sentido en el discurso político: un enfoque argumentativo. IDENTID ADES, No. 3, Año 2, diciembre, (2012), pp. 1-25.

- Antonio Gramsci: La politica y el Estado moderno, Diario Público (2009).

- Benjamín Arditi: “¿Populismo es hegemonía es política? La teoría del populismo de Ernesto Laclau”. Constellations, Vol. 17, No. 2 (2010), 488-497.

- Carlos Vilas: "¿Populismos reciclados o neoliberalismo a secas? El mito del "neopopulismo" latinoamericano" en Rev. Venez. de Econ. y Ciencias Sociales, 2003, vol. 9, nº 3 (mayo-agosto), pp.1336.

- Cristóbal Rovira y Raimundo Frei: "El populismo como experimento político: historia y teoría política de una ambivalencia" en Revista de Sociologia, $n^{\circ} 22$, Facultad de Ciencias Sociales - Universidad de Chile (2008). pp. 117-140.

- David Armitage: The Declaration of Independence: A Global History, Cambridge, MA: Harvard University Press (2007).

: Declaraciones de independencia, 1776-2011: del derecho natural al derecho internacional. En línea: http://scholar.harvard.edu/armitage/files/declaraciones.pdf (consultado 06/09/2015)

- David Howarth: "La teoría del discurso" en Marsh, David y Stoker, Gerry (eds.): Teoría y métodos de la ciencia política, Alianza (1995), pp. 125-142.

Politicae, No. 5 (2005) pp. 37-88.

"Aplicando la Teoría del Discurso: el Método de la Articulación" en Studia

- Emilio Rabasa Gamboa: La escuela de Cambridge: historia del pensamiento político. Una búsqueda metodológica. En-claves del pensamiento, año V, núm. 9, enero-junio (2011), pp. 157-180.

- Eric Hobsbawn: Naciones y nacionalismo desde 1780, Crítica (2000).

- Ernesto Laclau: La Razón Populista, FCE (2005).

(2009): Populismo: ¿qué nos dice un nombre? En Francisco Panizza (ed.), El

populismo como espejo de la democracia (pp. 51-70). Buenos Aires, Fondo de Cultura Económica. : Philosophical roots of discourse theory. En línea:

https://www.essex.ac.uk/centres/TheoStud/documents and files/pdf/Laclau\%20-

\%20philosophical $\% 20$ roots $\% 20$ of $\% 20$ discourse $\% 20$ theory.pdf

- Flavia Freidenberg: ¿Qué es el populismo? Enfoques de estudio y una nueva propuesta de definición como un estilo de liderazgo, Instituto de Iberoamérica USAL (2013). En línea:

http://www.academia.edu/2367975/ Qu\%C3\%A9 es el populismo Enfoques de estudio y un a_nueva_propuesta_de_definici $\% \mathrm{C} 3 \% \mathrm{~B} 3 \mathrm{n}$ _como_un_estilo_de_liderazgo

(consultado 20/08/2015).

- Francisco Alfaro Pareja: "El horizonte de las ilusiones populares: La Independencia de Venezuela y los conflictos no resueltos" en Historia Caribe, vol. IX no 24 Enero-Junio (2014), pp. 63-87.

- François-Xavier Guerra: Modernidad e independencias: ensayos sobre las revoluciones hispánicas. Madrid, MAPFRE (1992).

- Friedrich Nietzsche: Sobre verdad y mentira en sentido extramoral (1873) en línea:

https://www.lacavernadeplaton.com/articulosbis/verdadymentira.pdf

- Georges Lomné: De la República y otras repúblicas: La regeneración de un concepto. En Javier Fernández Sebastián (director): Diccionario politico y social del mundo iberoamericano: La era de las revoluciones, 1750-1850. Iberconceptos-I, Madrid, Centro de Estudios Políticos y Constitucionales (2015), pp. 12531369.

- Gerardo Aboy Carlés: "Las dos caras de Jano: acerca de la compleja relación entre populismo e instituciones políticas" en Pensamento Plural, $\mathrm{n}^{\circ} 7$ junho-dezembro (2010). 
: “Tensiones entre populismo y democracia liberal” en Área Teoría Política, Panel III: Populismo e identidades políticas en América Latina, $8^{\circ}$ Congreso Latinoamericano de Ciencia Política, Lima (2015).

- Hannah Arendt: Sobre la Revolución, Madrid, Alianza (1992).

- Íñigo Errejón: La lucha por la begemonía durante el primer gobierno del MAS en Bolivia (2006-2009): un análisis discursivo [Tesis Doctoral], UCM (2012).

- J. Hillis Miller: Hacerse cargo de una tarea. Momentos de decisión en el pensamiento de Ernesto Laclau. En Critchley, Simon y Marchart, Oliver (comp.): Laclau, aproximaciones críticas a su obra, FCE (2008), pp. 269-279.

- J. M Colomer: La teoría 'económica' de la política. En Vallespín, Fernando (ed.): Historia de la Teoría Política, Vol. 6 La reestructuración contemporánea del pensamiento político. Madrid, Alianza (1995).

- Javier Fdez. Sebastián: España, monarquía y nación. Cuatro concepciones de la comunidad política española entre el Antiguo Régimen y la Revolución liberal en Studia Historica-Historia Contemporánea, Vol. XII (1994), pp. 45-74.

: "La independencia de España y otras independencias. La transformación radical de un concepto en la crisis del mundo hispano", en Alfredo Ávila, Jordana Dym y Erika Pani: Las Declaraciones de Independencia: los textos fundamentales de las independencias americanas, El Colegio de México y Universidad Autónoma de México (2013), pp. 41-81.

- Javier Franzé: ¿Para qué sirven los clásicos? En Cuadernos Hispanoamericanos, 633, septiembre (2005), p. 114-121.

- Joao Feres Júnior: “El concepto de América, ¿concepto básico o contraconcepto?”, en Javier Fernández Sebastián (director): Diccionario político y social del mundo iberoamericano: La era de las revoluciones, 1750-1850. Iberconceptos-I, Madrid, Centro de Estudios Políticos y Constitucionales (2015), pp. 51-67. - John Markoff y Verónica Montecinos: "El irresistible ascenso de los economistas" en Desarrollo Económico, Vol. 34, No. 133, Apr. - Jun. (1994), pp. 3-29

- José Carlos Mariátegui: 7 ensayos de interpretación de la realidad peruana, Biblioteca Ayacucho (2007). - José María Portillo: "Independencia constituyente". En Ávila, Alfredo; Dym, Jordana; Pani, Erika: Las Declaraciones de Independencia: los textos fundamentales de las independencias americanas, El Colegio de México y Universidad Autónoma de México (2013) pp. 479-495.

- Julio Sevares: ¿Cooperación Sur-Sur o dependencia a la vieja usanza? en NUEVA SOCIEDAD, $\mathrm{N}^{\circ}$ 207 (2007), pp. 11-22.

- M. Belin, y V. Vázquez: "Independencia y estado-nación en Venezuela desde los regímenes de la gubernamentabilidad” en Documentos de trabajo IELAT, no 17 (2010), pp. 24-48.

- Manuel Lucena Salmoral: "El Siglo XIX: La utopía de libertad, orden y progreso" en Manuel Lucena Salmoral (coord.): Historia de Iberoamérica, Tomo III Historia Contemporánea, Madrid, Cátedra (1988).

- Michel Foucault: El orden del discurso, Barcelona Tusquets (1992).

- Milcíades Peña: Masas, Caudillos Y Elites La Dependencia Argentina De Yrigoyen A Perón, Buenos Aires, Fichas (1973).

- Quentin Skinner: Significado y comprensión en la historia de las ideas en Revista de Historia Intelectual, no 4 (2000), 149-191.

- Reinhart Koselleck: "Historia de los conceptos y conceptos de historia" en Ayer no 53 (2004), 2745.

- Sebastián Barros: "Espectralidad e Inestabilidad Institucional. Acerca de la Ruptura Populista" en Estudios Sociales, 30(1) (2006), pp. 145-162.

- VVAA (2013): Acta de Independencia de las Provincias Unidas de Venezuela. En Alfredo Ávila; Jordana Dym y Erika Pani: Las Declaraciones de Independencia: los textos fundamentales de las independencias americanas El Colegio de México y Universidad Autónoma de México, pp. 521-524. 